\title{
Corneal thickness changes during corneal collagen cross-linking with UV-A irradiation and hypo-osmolar riboflavin in thin corneas
}

\author{
Alterações na espessura da córnea durante "cross-linking" do colágeno com irradiação UV-A \\ e riboflavina hipo-osmolar em córneas finas
}

Belquiz Amaral Nassaralla ${ }^{1}$, Diogo Mafia Vieira ${ }^{1}$, Márcia leite Machado ${ }^{1}$, Marisa Novaes Faleiro Chaves de Figueiredo ${ }^{1}$, Joäo Jorge Nassaralla JR. ${ }^{1,2}$

\begin{abstract}
Purpose: To evaluate the thinnest corneal thickness changes during and after corneal collagen cross-linking treatment with ultraviolet-A irradiation, using hypo-osmolar riboflavin solution in thin corneas.

Methods: Eighteen eyes of 18 patients were included in this study. After epithelium removal, iso-osmolar $0.1 \%$ riboflavin solution was instilled to the cornea every 3 minutes for 30 minutes. Hypo-osmolar $0.1 \%$ riboflavin solution was then applied every 20 seconds for 5 minutes or until the thinnest corneal thickness reached $400 \mu \mathrm{m}$. Ultraviolet-A irradiation was performed for 30 minutes. During irradiation, iso-osmolar $0.1 \%$ riboflavin drops were applied every 5 minutes. Ultrasound pachymetry was performed at approximately the thinnest point of the cornea preoperatively, after epithelial removal, after iso-osmolar riboflavin instillation, after hypo-osmolar riboflavin instillation, after ultraviolet-A irradiation, and at 1 , 6 and 12 months after treatment.

Results: Mean preoperative thinnest corneal thickness was $380 \pm 11 \mu \mathrm{m}$. After epithelial removal it decreased to $341 \pm 11 \mu \mathrm{m}$, and after 30 minutes of iso-osmola $0.1 \%$ riboflavin drops, to $330 \pm 7.6 \mu \mathrm{m}$. After hypo-osmolar $0.1 \%$ riboflavin drops, mean thinnest corneal thickness increased to $418 \pm 11 \mu \mathrm{m}$. After UVA irradiation it was $384 \pm 10 \mu \mathrm{m}$. At 1, 6 and 12 months after treatment, it was $372 \pm 10 \mu \mathrm{m}$ $381 \pm 12.7$, and $379 \pm 15 \mu \mathrm{m}$, respectively. No intraoperative, early postoperative, or late postoperative complications were noted.

Conclusions: Hypo-osmolar $0.1 \%$ riboflavin solution seems to be effective for swelling thin corneas. The swelling effect is transient and short acting. Corneal thickness should be monitored throughout the procedure. Larger sample sizes and longer follow-up are required in order to make meaningful conclusions regarding safety.
\end{abstract}

Keywords: Keratoconus/therapy; Collagen/radiation effects; Riboflavin/therapeutic use; Ultraviolet therapy; Cross-linking reagents; Corneal pachymetry

\section{RESUMO}

Objetivo: Avaliar as alterações da espessura mínima da córnea durantee após o crosslinking do colágeno corneano com radiação ultravioleta A e solução hipo-osmolar de riboflavina em córneas finas.

Métodos: Dezoito olhos de 18 pacientes foram incluídos nesteestudo. Após a remoção do epitélio, solução iso-osmolar de riboflavina $0,1 \%$ foi instilada a cada 3 minutos por 30 minutos. Solução hipo-osmolar de riboflavina 0,1\% foi então aplicada a cada 20 segundos por 5 minutos ou até que a espessura mínima da córnea atingisse 400 um. Irradiação UVA foi feita durante 30 minutos. Durante a irradiação, riboflavina isoosmolar $0,1 \%$ foi aplicada a cada 5 minutos. Paquimetria ultrassônica foi realizada no ponto mais fino da córnea antes da cirurgia, após a remoção do epitélio, após a instilação de riboflavina iso-osmolar, após a instilação de riboflavina hipo-osmolar, após a irradiação com UVA e após 1, 6 e 12 meses do tratamento.

Resultados: Antes da cirurgia, a espessura mínima da córnea era de $380 \pm 11 \mu \mathrm{m}$. Após a remoção do epitélio, estevalor foi reduzido para $341 \pm 11$ um e após 30 minutos de riboflavina iso-osmolar, caiu para $330 \pm 7,6 \mu \mathrm{m}$. Após a riboflavina hipo-osmolar, a espessura mínima da córnea aumentou para $418 \pm 11 \mu \mathrm{m}$. Após a irradiação com UVA, era de $384 \pm 10 \mu \mathrm{m}$. Após 1, 6 e 12 meses do tratamento este valor era de $372 \pm$ $10,381 \pm 12,7$ e $379 \pm 15 \mu \mathrm{m}$, respectivamente. Não foram observadas complicações no intra ou no pós-operatório precoce ou tardio.

Conclusões: A solução de riboflavina hipo-osmolar 0,1\% parece ser eficaz para edemaciar córnea finas. Este efeito é transitório e de curta duração. A espessura da córnea deveria ser monitorada durante todo o procedimento. Maiornúmero de casose seguimento prolongado são necessários para tirarmos conclusões quanto à segurança.

Descritores: Ceratocone/terapia; Colágeno/efeitos de radiação; Riboflavina/uso terapêutico; Terapia ultravioleta; Reagentes para ligações cruzadas; Paquimetria da córnea

\section{INTRODUCTION}

Corneal collagen cross-linking $(\mathrm{CXL})$ therapy is a technique that uses a combination of riboflavin (vitamin B2) and ultraviolet-A light (UVA) to induce cross-linking in stromal collagen and thereby increases the mechanical rigidity of the cornea. The role of riboflavin in this method is dual. It works as a photosensitizer for the induction of cross-links and protects the underlying tissues from the deleterious influence of UVA irradiation. CXL is currently used to treat progressive corneal ectasia occurring in keratoconus ${ }^{(1-3)}$ or following laser refracti- ve surgery ${ }^{(4,5)}$. It is thought to work by enhancing the biomechanical properties of the tissue ${ }^{(1,2)}$ and its resistance to enzymatic digestion ${ }^{(6)}$.

The removal of the epithelium has been recommended as an initial step of the CXL procedure since its lipophilic nature reduces the diffusion of riboflavin into the corneal stroma ${ }^{(1-3)}$. Moreover, the epithelium may block UV rays ${ }^{(3)}$. The photosensitizer riboflavin is applied to the de-epithelialized surface of the cornea and allowed to penetrate into the corneal stroma ${ }^{(7,8)}$. The subsequent exposure of the cornea to UVA light is thought to result in photodynamic cross-lin-
Submitted for publication: June 14, 2012

Accepted for publication: March 21, 2013

Study carried out at Goiania Eye Institute.

Physician, Goiania Eye Institute, Goiânia (GO), Brazil.

2 Physician, Faculty of Health Sciences, University of Brasilia, Brasília (DF), Brazil.
Funding: No specific financial support was available for this study.

Disclosure of potential conflicts of interest: B.A.Nassaralla, None; D.M.Vieira, None; M.L.Machado, None; M.N.F.C.Figueiredo, None; J.J.Nassaralla Jr., None.

Correspondence address: Belquiz A. Nassaralla. Instituto de Olhos de Goiânia. Rua L, 53 - 12 은 andar, Setor Oeste - Goiânia (GO) - 74120-050 - Brazil

E-mails: bnassaralla@bol.com.br / nassaral@terra.com.br

Protocol ID: \#10/2012

Research Ethics Committee: Goiania Eye Institute, Goiania, Goias, Brazil

Protocol Registration ID: ClinicalTrials.gov ID- NTC01485211 
king when the riboflavin, excited by UVA, creates free radicals leading to cross-linking of collagen ${ }^{(7,8)}$.

The currently used treatment parameters induce cross-links in the anterior 250-350 $\mu \mathrm{m}$ of the corneal stroma ${ }^{(7)}$. Thus, to protect the endothelium and deeper ocular structures, CXL inclusion criteria require a minimal corneal thickness of $400 \mu \mathrm{m}$ after epithelium removal ${ }^{(7-9)}$. However, a recent modification to the technique, in which a hypo-osmolar riboflavin solution is applied to induce stromal swelling and increase stromal thickness prior to UVA irradiation, has enabled the treatment to be performed on thinner keratoconus corneas $(<400 \mu \mathrm{m})$ that would not have previously been eligible for riboflavin/UVA treatment $(9,10)$.

This prospective study evaluated the intraoperative pachymetric variations during the procedure and one year after CXL treatment with UVA irradiation, using hypo-osmolar riboflavin solution to induce stromal swelling and increase the stromal thickness before CXL in thin corneas with progressive keratoconus.

\section{METHODS}

Eighteen eyes of 18 patients, 11 men and 7 women, with progressive keratoconus and thinnest corneal thickness (TCT) less than $400 \mu \mathrm{m}$ (with the epithelium) were enrolled in this study. Mean patient age was $24 \pm 4.2$ years (range, $18-31$ years).

Patients with one of the following criteria after the preoperative examination were excluded: age younger than 16 or older than 35 years, corneal scars or opacities, pregnancy or lactation, active anterior segment pathologic features, previous corneal or anterior segment surgery, systemic connective tissue disease, ocular or systemic disease that could affect the epithelial healing, and dry eye syndrome. Patients using rigid contact lenses were asked to discontinue lens use for at least 3 weeks before the preoperative evaluation.

An increase of 1.00 diopter (D) in maximum topographic K-value (Kmax) and a reduction of corneal thickness with or without changes in uncorrected visual acuity (UCVA) and best-spectacle corrected visual acuity (BSCVA) within the last year were considered as indications of progression. Similarly, a decrease of 1.00 D in Kmax was considered as indication of regression.

Preoperative and postoperative examinations included: UCVA, BSCVA, slit-lamp biomicroscopy, Goldmann tonometry (Haag Streit, Bern, Swiss), fundus examination (Sigma 150K, Heine, Germany), specular microscopy (Konan, Hyogo, Japan), ultrasound pachymetry (CompuScan ${ }^{\mathrm{TM}}$ P, Storz, St. Louis, MO, USA), and corneal topography (Orbscan IIz, Technolas Perfect Vision GmbH).

The institutional ethics committee approved the study. All patients provided written informed consent in accordance with the Declaration of Helsinki after receiving a detailed description of the nature and risks of the treatment.

\section{TREATMENT}

Corneal CXL was conducted under sterile conditions in an operating room.

All patients received a mild oral sedative (diazepam $5 \mathrm{mg}$ ) $30 \mathrm{mi}$ nutes before surgery and two drops of topical $0.5 \%$ proximetacaine, 2 to 5 minutes before surgery. A wire eyelid speculum was placed for exposure. Corneal epithelium was removed by mechanical scraping over the central cornea $(9.0-\mathrm{mm}$ ) with a blunt Paton spatula (Storz Ophthalmic Instruments, St Louis, USA).

The lid speculum was removed. Iso-osmolar $0.1 \%$ riboflavin solution (402.7 mOsmol/L) with dextran T500 20\% was instilled to the cornea every 3 minutes for 30 minutes. A slit-lamp examination, using a blue filter, ensured the presence of riboflavin in the anterior chamber. Hypo-osmolar $0.1 \%$ riboflavin solution without dextran (310 mOsmol/L) was then applied every 20 seconds for 5 more minutes or until the thinnest corneal thickness (TCT) reached $400 \mu \mathrm{m}$.
The lid speculum was replaced. Fixation during irradiation was achieved by instructing the patient to focus on the light-emiting diode on the UVA emitter. The surgeon's thorough control ensured the patient's centration. Ultraviolet-A irradiation was performed for 30 minutes using a commercially available UVA system (UV-X, Peschke Meditrade) at a working distance of $5 \mathrm{~cm}$ with an irradiance of $3 \mathrm{~mW} / \mathrm{cm}^{2}$, corresponding to a surface dose of $5.4 \mathrm{~J} / \mathrm{cm}^{2}$. During irradiation, iso-osmolar $0.1 \%$ riboflavin drops were applied every 5 minutes to ensure saturation of the cornea with riboflavin. A topical anesthetic agent ( $0,5 \%$ proximetacaine) was applied as needed.

Three consecutive ultrasound pachymetry (CompuScan ${ }^{\mathrm{TM}} \mathrm{P}$, Storz, St. Louis, USA) measurements were obtained at approximately the thinnest point of the cornea, based on the Orbscan corneal topography and pachymetry maps, and the thinnest measurement was recorded. The probe tip of the pachymeter was held perpendicular to the cornea. Measurements were performed preoperatively, after epithelial removal, after iso-osmolar $0.1 \%$ riboflavin instillation, after hypo-osmolar $0.1 \%$ riboflavin instillation, after UVA irradiation, and at 1,6 and 12 months after CXL.

After treatment, patients were medicated with topical moxifloxacin $0.3 \%$ drops 4 times a day for 5 days, and ketorolac tromethamine 3 times a day for 3 days. Soft therapeutic lens was applied until complete re-epithelialization of the cornea. Unpreserved artificial tears were recommended for mild irritation. Paracetamol-codeine pain medication was also prescribed as needed for the first 2 to 3 days. Fluorometholone eyedrops were then applied 3 times a day for 2 weeks.

Postoperative examinations were scheduled daily until complete re-epithelialization and for 1, 6 and 12 months postoperatively.

Statistical analysis was performed using SPSS 17.0 (SPSS, Inc.) software package. The paired t-test was used to check the significance of the difference between two dependent groups for every continuous variable. The level of statistical significance was considered when $\mathrm{p}$-value was lower than 0.05 .

\section{RESULTS}

After treatment, complete re-epithelialization was observed within 4 days in all patients.

Twelve months after CXL, 12 eyes (66.6\%) had no change in their BSCVA compared to preoperative data, and 6 eyes (33.3\%) had an increase of 1 line on the log MAR scale $(P=0.013)$. No eye lost any line of the BSCVA, however, 38.8\% (7 eyes) of the fellow untreated eyes lost 1 line, and 5.5\% (1 eye) lost 2 lines on the logMAR scale in their BSCVA $(P=0.004)$.

The preoperative $(-6.0 \pm 2.6 \mathrm{D})$ and twelve months postoperative $(-5.6 \pm 2.7 \mathrm{D})$ mean spherical equivalent (SE) had a slight improvement by an average of $0.33 \mathrm{D}(P=0.004)$. In the fellow untreated eyes, mean SE increased by an average of $-0.5 D(P=0.000)$. Figure 1 shows the mean SE before and 1 year after treatment in the treated and untreated fellow eyes.

Mean preoperative TCT (with the epithelium) was $380 \pm 11 \mu \mathrm{m}$ (range, 363 to $398 \mu \mathrm{m}$ ). After epithelial removal (abrasion), it decreased to $341 \pm 11 \mu \mathrm{m}$ (range, 328 to $365 \mu \mathrm{m})$, ( $P=0.000)$. After 30 minutes of iso-osmolar $0.1 \%$ riboflavin drops instillation these values decreased to $330 \pm 7.6 \mu \mathrm{m}$ (range, 316 to $350 \mu \mathrm{m}$ ), with a mean TCT decrease of $10.9 \pm 6.2 \mu \mathrm{m}$ (range, 4 to $27 \mu \mathrm{m}$ ). Statistical analysis revealed significant difference when comparing these data with both, the preoperative and after abrasion values $(P=0.000)$.

After hypo-osmolar $0.1 \%$ riboflavin drops, all eyes achieved the minimum $400 \mu \mathrm{m}$ threshold of corneal thickness. However, the promptness of stromal swelling response and the amount of swelling showed distinct interindividual variation (5 minutes to 14 minutes; 52 to $101 \mu \mathrm{m}$ ). Mean TCT increased to $418 \pm 11 \mu \mathrm{m}$ (range, 400 to $446 \mu \mathrm{m}$ ), with a mean increase of $77 \pm 12.4 \mu \mathrm{m}$ (range, 52 to $101 \mu \mathrm{m}$ ). Statistical analysis revealed significant difference when comparing these values with those found before- $C X L(P=0.000)$, after abrasion $(P=0.000)$ and after iso-osmolar riboflavin drops $(P=0.000)$. 
After UVA irradiation, mean TCT was $384 \pm 10 \mu \mathrm{m}$ (range, 368 to $412 \mu \mathrm{m})$. Statistical analysis revealed a significant difference when comparing these results with those found after abrasion $(P=0.000)$, after iso-osmolar $(P=0.000)$, and after hypo-osmolar riboflavin drops $(P=0.000)$. However, no significant difference was found between mean TCT measurements before treatment and after UVA irradiation $(P=0.230)$.

At 1, 6 and 12 months after treatment, mean TCT was $372 \pm 10 \mu \mathrm{m}$ (range, 358 to $388 \mu \mathrm{m}$ ), $381 \pm 12.7$ (range, 362 to $402 \mu \mathrm{m}$ ), and 379 $\pm 13 \mu \mathrm{m}$ (range, 360 to $402 \mu \mathrm{m}$ ), respectively. Statistically significant difference was found between the data found before treatment and after 1 month ( $P=0.000)$. However, no statistically significant difference was noted in the TCT at $6(P=0.196)$ and 12 months after surgery $(P=0.847)$. Figure 2 shows the mean TCT (with standard deviation) during and after corneal CXL over time.

Twelve months after surgery, analysis of the maximum topographic K-readings (Kmax) showed no progression of the keratectasia in any treated eye. Slight regression was observed in 15 eyes (83.3\%). The mean Kmax decreased from $57.81 \pm 6.32 \mathrm{D}$ to $55.85 \pm 6.02 \mathrm{D}$, with an average reduction of $2.11 \pm 1.04 \mathrm{D}(P=0.000)$. In the fellow untreated eyes, however, 14 of 18 eyes (77.7\%) showed a continuous progression of the Kmax by an average of $1.63 \mathrm{D}(P=0.000)$. Figure 3 shows the mean Kmax before and 1 year after $C X L$, in the treated and fellow untreated eyes.

No statistically significant difference was found between the mean preoperative $(11.56 \pm 1.19 \mathrm{mmHg})$ and twelve months postoperative $(11.33 \pm 1.0 \mathrm{mmHg})$ intraocular pressure $(P=0.331)$.

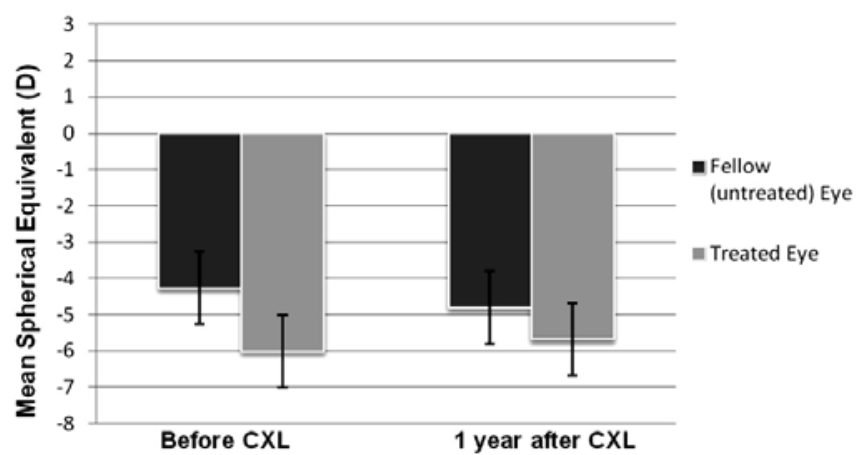

Figure 1. Average spherical equivalent before and one year after corneal collagen cross-linking with ultraviolet-A irradiation and hypo-osmolar riboflavin solution. There was a slight decrease in the mean spherical equivalent in the treated eyes (average: $0.33 \mathrm{D}$ ) and a slight increase in the fellow untreated eyes (average: $0.5 \mathrm{D}$ ).
The preoperative and postoperative (12 months) endothelial cell counts were $2228 \pm 385$ and $2287 \pm 284$ cells $/ \mathrm{mm}^{2}$, respectively $(P=0.32)$.

No intraoperative, early post-operative, or late postoperative complications were observed in this series of patients. After 12 months, all corneas remained transparent, without any scar in the stroma.

\section{DISCUSSION}

Corneal CXL has gained popularity as a temporary block in the progression of keratoconus. Preliminary results published in the literature indicate that when a series of safety precautions are taken, the technique has an excellent safety profile. These prerequisites are (1) de-epithelialization of the cornea to facilitate the diffusion and absorption of riboflavin, (2) use of riboflavin $0.1 \%$ for at least 30 minutes, (3) homogeneous UV irradiation and (4) a low minimum corneal thickness of $400 \mu \mathrm{m}$ after epithelium removal(7-9).

In many cases of progressive keratectasia, patients achieve a low minimum corneal thickness less than the threshold amount ( $<400 \mu \mathrm{m})$ that prohibits a safe CXL. Recent studies have shown that preoperative swelling of the cornea safely broadens the spectrum of $C X L$ indications to thin corneas that would not otherwise be eligible for treatment $t^{(9,10)}$. Corneal thickness was reported to increase by up to $30 \%$ after treatment ${ }^{(9)}$. This phenomenon is not due to an increase in the diameter of the collagen fibrils but rather to the hydrophilic capacities of the stromal proteoglycans, creating collagen-free "lakes"(11).

Some authors ${ }^{(12-14)}$ have shown that saturation of the corneal stroma using $0.1 \%$ iso-osmolar riboflavin solution and 30 minutes of UVA irradiation with a wavelenght of $370 \mathrm{~nm}$ and a surface irradiance of $3 \mathrm{~mW} / \mathrm{cm}^{2}$ may limit keratocyte death to a depth of approximately $300 \mu \mathrm{m}$. In our study, iso-osmolar riboflavin solution was applied to the de-epithelialized corneal surface, every 3 minutes for 30 minutes to ensure penetration of riboflavin into the corneal stroma. By means of slit lamp inspection using blue light, we could assure that riboflavin had appeared in the anterior chamber before UV-irradiation. The yellow staining of the anterior chamber served as a safety feature, indicating that riboflavin had penetrated the cornea and the cornea was thoroughly saturated. Then, hypo-osmolar riboflavin solution was applied to the cornea to induce stromal swelling, thus increasing the stromal thickness prior to UVA irradiation. Mean TCT increased to $418 \mu \mathrm{m}$ (range, 400 to $446 \mu \mathrm{m}$ ), reaching the threshold amount for a safe procedure.

Recent studies ${ }^{(15,16)}$ found significant TCT decrease of about 17 to $20 \%$ in central corneal thickness 30 minutes after iso-osmolar riboflavin drops. In their studies, a lid speculum was kept in the eye during the whole procedure. Another research ${ }^{(16)}$ showed a twostep TCT decrease of $19 \%$ during the 60 -minute treatment: a slower

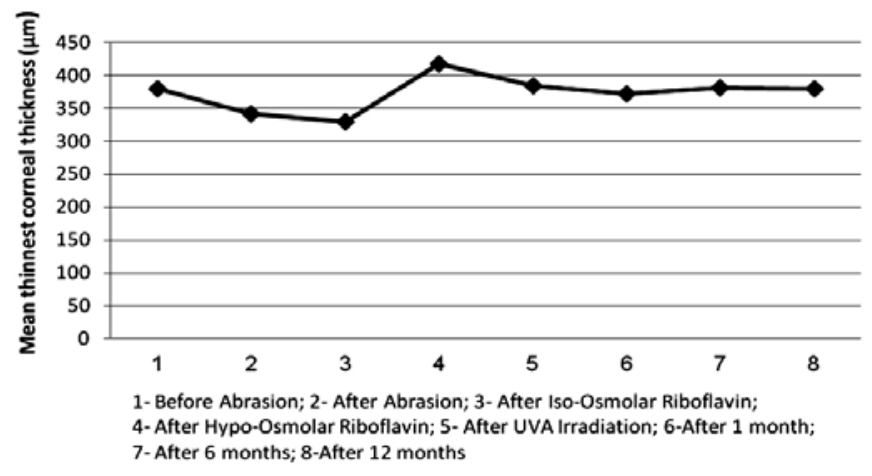

Figure 2. The mean thinnest corneal thickness changes during corneal collagen crosslinking with ultraviolet-A irradiation and hypo-osmolar riboflavin solution in thin corneas.

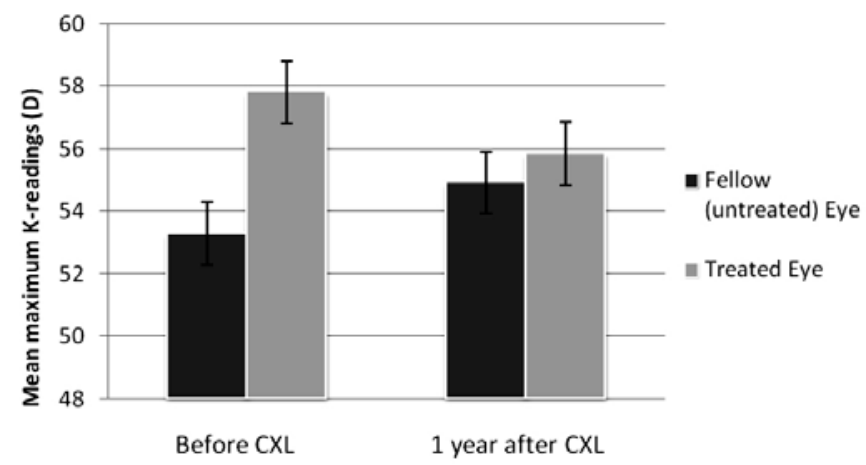

Figure 3. Change in the mean maximum topographic K-readings (Kmax) before and 1 year after CXL. There was an average reduction of 2.11D in the treated eyes and an average progression of 1.63 D in the fellow (untreated) eyes. 
thinning during riboflavin instillation (without a lid speculum) and a faster thinning when a lid speculum hold the lids open during UVA exposure. In all these studies, corneal exposure may have contributed to a higher corneal thickness decrease during the procedure and in the early postoperative CXL course. In order to reduce drying and dehydration of the cornea, we did not open the eye with a speculum during the first part of the treatment (i.e., after epithelium removal and before UVA irradiation). A small decrease of approximately 3\% in TCT after iso-osmolar riboflavin solution instillation was noted in our patients. It was probably due to the hyperosmolar effect of the dextran in a de-epithelialized cornea ${ }^{(15)}$. These results corroborate the statement of other authors ${ }^{(16)}$ who recommend that, during the first part of corneal $C X L$, the eyelid speculum is removed from the eye and the patient asked to keep the eye closed as much as possible to prevent evaporation of water from the corneal stroma.

After hypo-osmolar $0.1 \%$ riboflavin drops, mean TCT significantly increased to $418 \mu \mathrm{m}$, with a mean increase of $77 \pm 12.4 \mu \mathrm{m}$ (range, 52 to $101 \mu \mathrm{m}$ ). However, at the end of UVA irradiation, mean TCT had decreased to $384 \mu \mathrm{m}$, what is lower than the minimum $400 \mu \mathrm{m}$ required for safety. This artificial swelling effect is transient and it is not steady throughout the surgery. Nevertheless, this finding was not related to complications in this series of patients. However, as previously suggested ${ }^{(10,17)}$, the application of hypo-osmolar riboflavin solution should be continued during the entire process of irradiation to sustain the necessary concentration of the solution and to avoid any desiccation of the cornea.

In our analysis of the change in corneal thickness over time, pachymetric measurements thinned until 1 month postoperatively and appeared to increase after that. Six months after treatment, no statistically significant difference was found between the postoperative and baseline values. The physiology of this initial thinning and subsequent rethickening is unclear. Epithelial removal may increase the rate of water evaporation from the stroma and, as the stroma has no dehydration resistance, renders the cornea vulnerable to thinning ${ }^{(18,19)}$. Epithelial remodeling, anatomic and structural changes in corneal collagen fibrils ${ }^{(9,18)}$, and keratocyte apoptosis ${ }^{(13)}$, might be also implicated. A temporary increase in endothelial pump activity that may be caused by UVA exposure has been also suggested as a cause of the initial corneal thinning after $\mathrm{CXL}^{(17)}$.

Surgeons must be aware about the intraoperative and postoperative thinning of the cornea after $C X \mathrm{~L}$, especially in thinner corneas (less than $400 \mu \mathrm{m}$ ). Therefore, corneal thickness should be monitored throughout the procedure, and in case of readings lower than $400 \mu \mathrm{m}$ at any point during treatment, the cornea should be re-swelled by administering the riboflavin hypotonic solution.

Statistical analysis revealed a slight, but statistically significant improvement in SE, corneal steepness and visual performance as determined by the BSCVA. Our results are modest in light of the results from previous studies in which corneas of a thickness of more than $400 \mu \mathrm{m}$ treated with iso-osmolar riboflavin solution, resulted in significantly better improvements in such parameters. However, the aim of the current study was not to cause improvement, but to broaden the spectrum of CXL indications to corneas that would otherwise not be eligible for CXL treatment, halting progression of keratoconus and preserving usable visual acuity.

\section{CONCLUSIONS}

Hypo-osmolar $0.1 \%$ riboflavin solution seems to be effective for swelling thin corneas that would otherwise not be eligible for CXL treatment. However, the swelling effect is transient and short acting. Corneal thickness should be monitored throughout the procedure. Larger sample sizes and longer follow-up are required in order to make meaningful conclusions regarding safety, stability and efficacy of the procedure in these artificially swollen corneas.

\section{REFERENCES}

1. Spoerl E, Huhle M, Seiler T. Induction of cross-links in corneal tissue. Exp Eye Res. 1998 66(1):97-103.

2. Wollensak G, Spoerl E, Seiler T. Stress-strain measurements of human and porcine corneas after riboflavin-ultraviolet-A-induced cross-linking. J Cataract Refract Surg. 2003, 29(9):1780-85.

3. Wollensak G, Spoerl E, Seiler T. Ribofloavin/ultraviolet-a-induced collagen cosslinking for the treatment of keratoconus. Am J Ophthalmol. 2003;135(5):620-7.

4. Hafezi F, Kanellopoulos J, Wiltfang R, Seiler T. Corneal collagen cross-linking with riboflavin and ultraviolet A to treat induced keratectasia after laser in situ keratomileusis. J Cataract Refract Surg. 2007;33(12):2035-40. Comment in: J Cataract Refract Surg. 2008;34(6):879; author reply 879.

5. Salgado J, Khoramnia R, Lohmann C, Winkler von Mohrenfels C. Corneal collagen cross linking in post-LASIK keratectasia. Br J Ophthalmol. 2011;95(4):493-97. Comment in: Br J Ophthalmol. 2011;95(12):1759-60.

6. Spoerl E, Wollensak G, Seiler T. Increased resistance of cross-linked cornea against enzymatic digestion. Curr Eye Res. 2004;29(1):35-40.

7. Spoerl E, Mrochen M, Sliney D, Trokel S, Seiler T. Safety of UVA-riboflavin cross-linking of the cornea. Cornea. 2007;26(4):385-9. Comment in: J Refract Surg. 2012;28(2):91-2

8. Hayes S, O'Brart D, Lamdin L, Doutch J, Samaras K, Marshall J, et al. Effect of complete epithelial debridement before riboflavin-ultraviolet-A corneal collagen cross linking therapy. J Cataract Refract Surg. 2008;34(4):657-61. Comment in: J Cataract Refract Surg. 2008;34(12):2008-9; author reply 2009. J Cataract Refract Surg. 2008;34(11):1815-6; author reply 1816

9. Hafezi F, Mrochen M, Iseli HP, Seiler T. Collagen crosslinking with ultraviolet-A and hypoosmolar riboflavin solution in thin corneas. J Cataract Refract Surg. 2009:35(4):621-4

10. Raiskup F, Spoerl E. Corneal cross-linking with hypo-osmolar riboflavin solution in thin keratoconic corneas. Am J Ophthalmol. 2011;152(1):28-32.

11. Dohlman $\mathrm{CH}$. Physiology of the cornea: corneal edema. In: Smolin G, Thoft RA, editors. The Cornea: Scientific Foundations and Clinical Practice. $2^{\text {nd }}$ ed. Boston, MA Little, Brown and Company; 1987. p.3-16.

12. Koller T, Mrochen M, Seiler T. Complication and failure rates after corneal cross-linking. J Cataract Refract Surg. 2009;35(8):1358-62. Comment in: J Cataract Refract Surg. 2010;36(1):185; author reply 186.

13. Wollensak G, Spoerl E, Wilsch M, Seiler T. Keratocyte apoptosis after corneal collagen cross-linking using riboflavin/UVA treatment. Cornea. 2004;23(1):43-9.

14. Wollensak G, Spoerl E, Reber F, Pillunat L, Funk R. Corneal endothelial cytotoxicity of riboflavin/UVA treatment in vitro. Ophthalmic Res. 2003;35(6):324-8.

15. Kymionis GD, Kounis GA, Portaliou DM, Gretzelos MA, Karavitaki AE, Coskunseven E, et al. Intraoperative pachymetric measurements during corneal collagen cross-linking with riboflavin and ultraviolet A irradiation. Ophthalmology. 2009;116(12):2336-9. Comment in: Ophthalmology. 2010;117(10):2040-1; author reply 2041. Ophthalmology. 2010;117(10):2041, 2041.e1; author reply 2041-2.

16. Kaya V, Utine CA, Yilmaz OF. Intraoperative corneal thickness measurements during corneal collagen cross-linking with hypoosmolar riboflavin solution in thin corneas. Cornea. 2012;31(5):486-90. Comment in: Cornea. 2013;32(1):110. Cornea. 2012;31(12):1508-9.

17. Holopainen JM, Krootila K. Transient corneal thinning in eyes undergoing corneal cross-linking. Am J Ophthalmol. 2011;152(4):533-36. Comment in: Am J Ophthalmol. 2012;153(2):383; author reply 383-4.

18. Wollensak G, Aurich H, Pham DT, Wirbelauer C. Hydration behavior of porcine cornea cross-linked with riboflavin and ultraviolet A. J Cataract Refract Surg 2007;33(3):516-21. Comment in: J Cataract Refract Surg. 2007;33(9):1503. J Cataract Refract Surg. 2008; 34(6):879-80.

19. Wollensak G, Spoerl E, Reber F, Seiler T. Keratocyte cytotoxicity of riboflavin/UVA-treatment in vitro. Eye (Lond). 2004;18(7):718-22 